\title{
A double stable isotope technique for measuring iron absorption in infants
}

\author{
BY PETER KASTENMAYER ${ }^{1 *}$, LENA DAVIDSSON ${ }^{1}$, PILAR GALAN ${ }^{2}$, \\ FRANÇOISE CHEROUVRIER ${ }^{2}$, SERGE HERCBERG ${ }^{2}$ \\ AND RICHARD F. HURRELL ${ }^{1}$ \\ ${ }^{1}$ Nestlé Research Centre, PO Box 44, CH-1000 Lausanne 26, Switzerland \\ ${ }^{2}$ Centre de Recherche sur les Anémies Nutritionnelles, CNAM, 2 rue Conté, F-75003 Paris, France
}

(Received 7 December 1992 - Revised 7 April 1993 - Accepted 10 May 1993)

\begin{abstract}
A stable isotope technique has been developed which uses ${ }^{57} \mathrm{Fe}$ and ${ }^{58} \mathrm{Fe}$ as labels and which enables the simultaneous measurement of Fe absorption from two test meals in infants. The method was evaluated by measuring Fe absorption from a commercial whey-adjusted infant formula in nine healthy infants aged 13-25 weeks. Each infant was fed $210 \mathrm{ml}$ formula, labelled with either ${ }^{57} \mathrm{Fe}$ or ${ }^{58} \mathrm{Fe}$, on four consecutive mornings, in random order. The total Fe content in each feed was $2.5 \mathrm{mg} \mathrm{Fe}$; either as $2.5 \mathrm{mg}$ ${ }^{57} \mathrm{Fe}$, or $0.6 \mathrm{mg}{ }^{58} \mathrm{Fe}$ plus $1.9 \mathrm{mg}$ Fe with normal isotopic composition. Isotopic enrichment of $\mathrm{Fe}$ in erythrocytes was measured by thermal ionization mass spectrometry $14 \mathrm{~d}$ after the last administration, and $\mathrm{Fe}$ absorption was calculated based on isotope ratio shifts, total circulating $\mathrm{Fe}$ and intake of each isotope. Geometric mean absorption for the ${ }^{57} \mathrm{Fe}$ and ${ }^{58} \mathrm{Fe}$ labels was 6.72 and $6.58 \%$ respectively, and the absorption of the two isotopes was not significantly different (Student's paired $t$ test). By this technique, paired comparisons of Fe absorption can be obtained and systematic studies of the influence of dietary factors on Fe absorption during infancy can be conducted.
\end{abstract}

Iron: Stable isotopes: Infants: Thermal ionization mass spectrometry

Maintaining adequate Fe nutrition is a major problem early in life, and after weaning there is a high risk of Fe deficiency (Dallman et al. 1980). Although Fe absorption in adults is relatively well documented, very little information about Fe absorption and metabolism in infants is available (Fomon et al. 1989). This lack of data is largely due to the restrictive use of radioisotopes in infants because of ethical considerations and to the methodological problems involved in balance studies. The metabolic balance technique is not a useful approach for measuring Fe absorption because of the low fractional absorption of this element. Stable isotopes offer an alternative to radioisotopes and could be an ideal approach when studying mineral absorption in infants and other population groups for which radioisotopes should be restricted (Janghorbani \& Ting, 1990).

Natural $\mathrm{Fe}$ has four stable isotopes $\left({ }^{54} \mathrm{Fe},{ }^{56} \mathrm{Fe},{ }^{57} \mathrm{Fe}\right.$, and $\left.{ }^{58} \mathrm{Fe}\right)$, two of which have a low enough natural abundance to be used as labels when measuring absorption; ${ }^{57} \mathrm{Fe}(22 \mathrm{~g} / \mathrm{kg}$ total $\mathrm{Fe})$ and ${ }^{58} \mathrm{Fe}(2.8 \mathrm{~g} / \mathrm{kg}$ total $\mathrm{Fe})$ (De Bièvre \& Barnes, 1985). Fomon et al. (1988) have recently proposed a method using the incorporation of ${ }^{58} \mathrm{Fe}$ into erythrocytes to measure $\mathrm{Fe}$ absorption in infants. However, they reported a relatively large inter-individual variation in $\mathrm{Fe}$ absorption suggesting the need for a technique where each infant acts as his 
or her own control. With only one isotope it is possible to make repeated administrations with a time lapse of at least 2 weeks between test meals. However, changes of $\mathrm{Fe}$ status in the rapidly growing child could influence absorption between administrations and therefore result in data which would be difficult to interpret. A double-isotope technique would thus be preferred and such a technique is routinely used in adult subjects using radioisotopes (Cook et al. 1972; Hallberg \& Björn-Rasmussen, 1972). Using this technique, subjects with widely different $\mathrm{Fe}$ status can be studied since Fe absorption from two different test meals is measured simultaneously in the same subject.

The aim of the present study was to develop a double-isotope technique for measuring Fe absorption in infants using the stable isotopes ${ }^{57} \mathrm{Fe}$ and ${ }^{58} \mathrm{Fe}$. The isotopes were administered on consecutive days in identical feeds of infant formula and enrichment of erythrocyte haemoglobin was measured by thermal ionization mass spectrometry (TIMS) $14 \mathrm{~d}$ after administration.

\section{MATERIALS AND METHODS \\ Preparation of labels}

Elemental $\mathrm{Fe}$ enriched with ${ }^{57} \mathrm{Fe}(95 \cdot 3 \%)$ was purchased from Medgenix Diagnostics (Ratingen, Germany). A total of $70.2 \mathrm{mg} \mathrm{Fe}$ was dissolved in $2 \mathrm{ml} 7 \mathrm{M}-\mathrm{HNO}_{3} ; 8.75 \mathrm{ml}$ $0.5 \mathrm{M}-\mathrm{H}_{2} \mathrm{SO}_{4}$ was then added and the solution was heated to dryness at $120^{\circ}$. After further heating for $30 \mathrm{~min}$ at both $230^{\circ}$ and $500^{\circ}$ followed by cooling, the white powder was dissolved in $17 \mathrm{ml} 0.2 \mathrm{M}^{-\mathrm{H}_{2}} \mathrm{SO}_{4}$. To remove impurities the solution was filtered through a $0.5 \mu \mathrm{m}$ Teflon filter (Millex-FH13; Millipore, Zürich, Switzerland). $\mathrm{Fe}^{3+}$ was reduced to $\mathrm{Fe}^{2+}$ by adding ascorbic acid (Merck, Darmstadt, Germany) at a molar ratio of $1: 1$ (Sevenich \& Fritz, 1985) and the solution was finally diluted to $70 \mathrm{ml}$ to give an $\mathrm{Fe}$ concentration of approximately $1 \mathrm{mg} / \mathrm{ml}$.

The Fe concentration was measured by atomic absorption spectrophotometry (AAS; model 975; Varian Techtron, Mulgrave, Australia) and the isotopic composition by TIMS. The solution was de-aerated with $\mathrm{N}_{2}$, dispensed into $5 \mathrm{ml}$ Reacti-vials (Pierce, Rockford, IL, USA), and stored at $4^{\circ}$ until administration. Each child received $5 \mathrm{ml}$ of this solution (containing $5.075 \mathrm{mg}$ total $\mathrm{Fe}, 4.836 \mathrm{mg}{ }^{57} \mathrm{Fe}$ and $0.122 \mathrm{mg}{ }^{58} \mathrm{Fe}$ ) added in two equal parts $(2.5 \mathrm{ml} / \mathrm{feed})$ to the two feeds of infant formula at the time of feeding.

Enriched ${ }^{58} \mathrm{Fe}$ was purchased as $\mathrm{Fe}_{2} \mathrm{O}_{3}$ (Oak Ridge National Laboratory, Oak Ridge, TN, USA). A quantity of $28.2 \mathrm{mg} \mathrm{Fe}_{2} \mathrm{O}_{3}$ was dissolved in $1.8 \mathrm{ml} 10 \cdot 2 \mathrm{M}-\mathrm{HCl}$ and $1 \mathrm{ml} 14.5 \mathrm{M}-\mathrm{HNO}_{3}$,

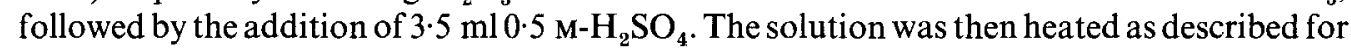
the ${ }^{57} \mathrm{Fe}$ label. The white powder was redissolved in $7.8 \mathrm{ml} 0.2 \mathrm{M}-\mathrm{H}_{2} \mathrm{SO}_{4}$ and filtered. After addition of ascorbic acid (molar ratio $1: 1$ ) the volume was adjusted to $28 \mathrm{ml}$ and the $\mathrm{Fe}$ concentration as well as the isotopic composition were determined as described for ${ }^{57} \mathrm{Fe}$.

The amount of ${ }^{58} \mathrm{Fe}$ which had to be administered to get sufficient enrichment of erythrocytes was much less than that for ${ }^{57} \mathrm{Fe}$ because of the lower natural abundance of ${ }^{58} \mathrm{Fe}$. In order to keep the volume and the Fe concentration of the formula constant, the ${ }^{58} \mathrm{Fe}$ solution was diluted with $\mathrm{Fe}$ of natural isotopic composition. A solution of $\mathrm{FeSO}_{4} .7 \mathrm{H}_{2} \mathrm{O}$ (Merck) with the same Fe concentration as the ${ }^{58} \mathrm{Fe}$ label and a content of $0.5 \mathrm{~mol}$ ascorbic acid $/ \mathrm{mol} \mathrm{Fe}$ was prepared. Weighed amounts of both solutions were mixed, de-aerated with $\mathrm{N}_{2}$ and dispensed into $5 \mathrm{ml}$ vials. A total of $5.09 \mathrm{ml}$ solution (containing $5.075 \mathrm{mg}$ total $\mathrm{Fe}, 1.196 \mathrm{mg}{ }^{58} \mathrm{Fe}$ and $0.131 \mathrm{mg}{ }^{57} \mathrm{Fe}$ ) was added to the two feeds $(2.545 \mathrm{ml} / \mathrm{feed})$ of infant formula administered to each infant. 
Table 1. Sex, age, weight and Fe status of subjects on day 1 of study

\begin{tabular}{|c|c|c|c|c|c|}
\hline Subject & Sex & $\begin{array}{c}\text { Age } \\
\text { (weeks) }\end{array}$ & $\begin{array}{l}\text { Weight } \\
(\mathrm{kg})\end{array}$ & $\begin{array}{l}\text { Haemoglobin } \\
\qquad(\mathrm{g} / \mathrm{l})\end{array}$ & $\begin{array}{l}\text { Serum } \\
\text { ferritin } \\
(\mu \mathrm{g} / \mathrm{l})\end{array}$ \\
\hline A & $\mathbf{M}$ & 22 & $7 \cdot 80$ & 117 & 16.6 \\
\hline B & $\mathbf{M}$ & 22 & $7 \cdot 56$ & 114 & $1 \cdot 0$ \\
\hline C & $\mathrm{F}$ & 15 & 6.00 & 112 & 12.6 \\
\hline D & $\mathbf{M}$ & 25 & 6.92 & 106 & 1.0 \\
\hline $\mathrm{E}$ & $\mathrm{F}$ & 14 & $6 \cdot 60$ & 112 & 73.6 \\
\hline $\mathrm{F}$ & $\mathrm{F}$ & 20 & $7 \cdot 31$ & 109 & 36.2 \\
\hline $\mathrm{G}$ & $M$ & 22 & 8.02 & 109 & 40.0 \\
\hline $\mathrm{H}$ & $\mathrm{F}$ & 15 & $7 \cdot 53$ & 113 & 29.1 \\
\hline I & $\mathbf{M}$ & 13 & 6.00 & 128 & 85.6 \\
\hline
\end{tabular}

\section{Subjects}

Nine infants were recruited at a local health centre in Paris. All infants were apparently healthy and living at home with their parents. The sex, age, weight and $\mathrm{Fe}$ status of the subjects are shown in Table 1. Two infants had little or no storage $\mathrm{Fe}$ as indicated by the serum ferritin measurement and three had marginally low erythrocyte haemoglobin concentrations $(<110 \mathrm{~g} / 1)$. The mean age of the children was 19 weeks (range 13-25 weeks) at the time of the administrations. All children were given a commercial whey-adjusted cow's milk formula with $8 \mathrm{mg} \mathrm{Fe} / 1$ (Nidina 1; Nestlé, Paris, France) for a period of at least 3 weeks before the study. Some of the children were still partly breast-fed and small amounts of solids had been introduced into the diets of the older children. The study was approved by the ethical committee of the Centre de Recherche sur les Anémies Nutritionnelles, CNAM, Paris. The purpose of the study and all procedures were explained to the parents orally and by written information, and informed consent was obtained from all parents.

\section{Test meal}

A whey-adjusted infant formula (PreBeba; Nestlé, Frankfurt, Germany) without added Fe was used for the administrations of stable isotopes. Ascorbic acid concentration was $80 \mathrm{mg} / 1$ and each feed consisted of $210 \mathrm{ml}$ formula. The spray-dried powder was diluted with boiled, deionized distilled water according to the instructions given by the manufacturer ( $14 \mathrm{~g}$ powder plus $90 \mathrm{~g}$ water gives $100 \mathrm{ml}$ formula). The formula was labelled with the enriched isotopes immediately before administration.

\section{Study design}

On the mornings of days $1-4$, each infant received one formula feed labelled with either ${ }^{57} \mathrm{Fe}$ $(2.418 \mathrm{mg})$ or ${ }^{58} \mathrm{Fe}(0.598 \mathrm{mg})$. Each labelled formula was given twice, either on days 1 and 3 or days 2 and 4 . The formula was given after an overnight fast and no food or liquid was allowed for a period of at least $2 \mathrm{~h}$ following each administration. The labelled test meals were given under close supervision of the investigators at the health centre. Preweighed feeding bottles and bibs were used to estimate losses during administrations. For standardization, the meal following each labelled test meal consisted of a portion of the whey-adjusted formula normally consumed by the infants (Nidina 1) and was provided by the investigators. Venous blood samples were drawn on days 1 and 18 for analysis of stable isotope ratios in erythrocytes. Tubes without any additives were used when drawing blood. 
Blood samples were frozen and stored at $-18^{\circ}$ until analysis. Body weight was registered on days 1 and 18.

\section{Preparation of blood samples for mass spectrometric analysis}

All enriched blood samples taken at day 18 were analysed in duplicate. Baseline Fe ratios were determined on blood samples drawn on day 1 for six of the nine infants.

The samples of whole blood were mineralized using a microwave digestion system (MDS-81D; CEM Corporation, Matthews, NC, USA). Approximately $400 \mathrm{mg}$ thawed blood was weighed into the $120 \mathrm{ml}$ Teflon digestion vessels, $5 \mathrm{ml}$ concentrated $\mathrm{HNO}_{3}$ was added and vessels were closed on the capping station. In order to obtain a clear, colourless digest a two-step heating procedure was required. The first step involved a $14 \mathrm{~min}$ power ramp from $268 \mathrm{~W}$ to $595 \mathrm{~W}$. After 5 min cooling time the vessels were vented and $2 \mathrm{ml}_{2} \mathrm{O}_{2}$ ( $300 \mathrm{ml} / \mathrm{l}$ ) was added, followed by further heating for $5 \mathrm{~min}$ at $268 \mathrm{~W}$ and then $5 \mathrm{~min}$ at $536 \mathrm{~W}$. The clear digest was transferred to Teflon tubes and evaporated to dryness under filtered $\mathrm{N}_{2}$. The samples were dissolved twice in $5 \mathrm{ml}$ concentrated $\mathrm{HCl}$ and heated to dryness before finally being taken up in $6 \mathrm{ml} 5 \mathrm{M}-\mathrm{HCl}$.

Fe was separated from matrix elements by anion exchange chromatography, using a modified method of Fasset et al. (1984). Econo columns (Bio-Rad Laboratories, Glattbrugg, Switzerland), inner diameter $7 \mathrm{~mm}$, were filled to a height of $70 \mathrm{~mm}$ with anion exchange resin (Type AG1-X8, 200-400 mesh, Cl-form, Bio-Rad). The resin was washed with $60 \mathrm{ml} 2 \mathrm{M}-\mathrm{HNO}_{3}$ using an Ismatec IPN 4 peristaltic pump (Ismatec SA, Zürich, Switzerland) at a flow rate of $1 \mathrm{ml} / \mathrm{min}$ and then regenerated to the chloride form with $100 \mathrm{ml}$ $1 \mathrm{M}-\mathrm{HCl}$. After addition of the sample, the column was washed with $30 \mathrm{ml} 5 \mathrm{M}-\mathrm{HCl}$ and the Fe was eluted with $20 \mathrm{ml} 1 \mathrm{M}-\mathrm{HNO}_{3}$. Total $\mathrm{Fe}$ was determined in the Fe fractions by AAS. Samples were then evaporated to dryness in Teflon tubes under a stream of filtered $\mathrm{N}_{2}$ and redissolved in $0.1 \mathrm{M}-\mathrm{HNO}_{3}$ to give a concentration of $3 \mu \mathrm{g} \mathrm{Fe} / \mu \mathrm{l}$.

To check for contamination of samples during processing, chemistry blanks were measured using an ${ }^{57} \mathrm{Fe}$ enriched spike $(95 \cdot 3 \%)$. A precisely known amount of spike was put through all the procedures used for sample preparation and the change of the isotopic composition was determined by TIMS.

All acids used were purified by sub-boiling distillation in a quartz still (Kürner Analysentechnik, Rosenheim, Germany). Other chemicals were analytical grade purity, except the $\mathrm{H}_{2} \mathrm{O}_{2}$ solution which was suprapure. Only ultra-pure water (18 M $\Omega$ ) was used (Milli-Q water system; Millipore AG, Zürich, Switzerland). To minimize contamination through vessel materials, only acid-washed quartz, Teflon and polyethylene containers were used during all procedures.

\section{Preparation of enriched standards}

A set of standards was prepared for the enriched isotopes ${ }^{57} \mathrm{Fe}$ and ${ }^{58} \mathrm{Fe}$. A standard reference solution (Merck) with a certified Fe concentration of $1.000 \mathrm{~g} / 1$ was diluted with $0 \cdot 1 \mathrm{M}-\mathrm{HNO}_{3}$ to give a concentration of $25 \mu \mathrm{g} \mathrm{Fe} / \mathrm{ml}$. Enriched isotope solutions were prepared by dissolving ${ }^{57} \mathrm{Fe}$-enriched metal and ${ }^{58} \mathrm{Fe}$-enriched $\mathrm{Fe}_{2} \mathrm{O}_{3}$ in $0.5 \mathrm{ml} 14.5 \mathrm{M}-\mathrm{HNO}_{3}$ and $2 \mathrm{ml} 10 \cdot 2 \mathrm{M}-\mathrm{HCl}$. The concentration of the enriched isotope solutions was determined by reverse isotope dilution, using the standard reference solution. Enriched standards were prepared by weighing the diluted standard reference solution and different quantities of enriched solutions into acid-washed Teflon vials. The enrichment for each set of standards was chosen to include a range of enrichments expected in the blood samples. Isotopic ratios of enriched isotope solutions, of the natural reference solution and of enriched standards 
were determined by TIMS. Isotopic enrichment of standards was then calculated using the concentration and the isotopic composition of the natural reference solution and the pure spike solutions.

\section{Mass spectrometric analysis}

Isotope ratios were measured with a computer-controlled thermal ionization mass spectrometer (Model THQ; Finnigan MAT, Bremen, Germany) equipped with a secondary electron multiplier (SEM), a 13-sample turret and a reference pyrometer. Re filaments of $0.04 \times 0.7 \mathrm{~mm}$, purity $99.98 \%$ (Wagner Analysentechnik, Worpswede, Germany) were cleaned by out-gassing in a bakeout device (Finnigan MAT) under vacuum at $4.5 \mathrm{~A}$ for $20 \mathrm{~min}$ to remove impurities. Samples were loaded onto filaments in a laminar flow bench (Model Gelaire twin 30; Scan AG, Basel, Switzerland). During loading the filaments were heated by a power-supply (Finnigan MAT) to evaporate the acid. Fe was analysed using single filaments and a silica gel ionization enhancement technique (Götz \& Heumann, 1987) slightly modified by addition of $\mathrm{Al}$ which increases the ion yield (Beer \& Heumann, 1992). Silica gel was made according to the procedure of Barnes et al. (1973) and further concentrated by reducing the volume of the suspension to one-third. Silica gel $(5 \mu \mathrm{l})$ was loaded onto the filament, heated to dryness at $1.2 \mathrm{~A}$ and $1 \mu \mathrm{l}$ of $\mathrm{Al}\left(\mathrm{NO}_{3}\right)_{3}$ solution (Merck) containing $3 \mu \mathrm{g}$ of $\mathrm{Al}$ was added. Sample $(2 \mu \mathrm{l} ; 6 \mu \mathrm{g} \mathrm{Fe})$ was deposited into the white silica gel layer and dried at $0.8 \mathrm{~A}$. Finally, $0.5 \mu \mathrm{l}$ saturated $\mathrm{H}_{3} \mathrm{BO}_{3}$ solution was placed on the filament and heated for $1 \mathrm{~min}$ at $0.8 \mathrm{~A}, 1.2 \mathrm{~A}$ and $1.5 \mathrm{~A}$.

Samples were analysed automatically under computer control. The filament was heated to $1320^{\circ}$ within $30 \mathrm{~min}$ to obtain a beam of $3-5 \mathrm{~V}$ on the SEM operated at an amplification of 25 relative to the Faraday detector. Three blocks with twelve scans each across the isotope pattern were collected in the peak jumping mode. Data were analysed for outliers by a Dixon test (Dixon \& Massey, 1969). Measurements which had an internal standard deviation greater than the target precision of $0.5 \%$ for the ${ }^{57} \mathrm{Fe}:{ }^{56} \mathrm{Fe}$ ratio and $1 \%$ for the ${ }^{58} \mathrm{Fe}:{ }^{56} \mathrm{Fe}$ ratio were discarded and analysis was repeated.

Enriched standards were measured in triplicate, baseline and enriched blood samples once. The natural isotopic composition of $\mathrm{Fe}$ was determined on Fe isolated from blood (Reference material A-13; Animal blood; International Atomic Energy Agency, Vienna, Austria) and on Fe from an Fe standard solution (Merck). Enriched blood samples were always measured in close conjunction with two baseline samples which were averaged to give the baseline ratio.

The quantity of administered ${ }^{58} \mathrm{Fe}$ and ${ }^{57} \mathrm{Fe}(\mathrm{mg})$ incorporated into erythrocytes $\left(\mathrm{Fe}_{(\mathrm{inc})}\right)$ on day 18 was calculated in a manner similar to that used by Fomon et al. (1988):

$$
\begin{aligned}
& { }^{57} \mathrm{Fe}_{(\mathrm{inc})}=\frac{R^{t} 57: 56-R^{0} 57: 56}{R^{0} 57: 56} \times \mathrm{Fe}_{(\text {(eirc) }} \times \mathrm{A}_{57}, \\
& { }^{58} \mathrm{Fe}_{(\mathrm{inc})}=\frac{R^{t} 58: 56-R^{0} 58: 56}{R^{0} 58: 56} \times \mathrm{Fe}_{(\text {(irc) }} \times \mathrm{A}_{58},
\end{aligned}
$$

where $R^{t} 57: 56$ and $R^{t} 58: 56$ are the enriched isotope ratios at time $t$ after administration of dose (day 18); $R^{0} 57: 56$ and $R^{\circ} 58: 56$ are the measured baseline ratios (day 1 ); $\mathrm{Fe}_{(\mathrm{circ})}$ is the quantity of total circulating $\mathrm{Fe}(\mathrm{mg})$ at day $18 ; \mathrm{A}_{57}$ and $\mathrm{A}_{58}$ are the measured natural abundances of ${ }^{57} \mathrm{Fe}(0.0214)$ and ${ }^{58} \mathrm{Fe}(0.00287)$ expressed as weight fractions.

The quantity of total circulating Fe $(\mathrm{mg})$ was estimated as:

$$
\mathrm{Fe}_{(\mathrm{cire})}=\mathrm{BVol} \times \mathrm{Hb} \times 3.47 \text {, }
$$


where $\mathrm{BVol}$ is the blood volume ( $\mathrm{ml}$ ) assumed to be $65 \mathrm{ml} / \mathrm{kg}$ (Fomon et al. 1988), $\mathrm{Hb}$ is the haemoglobin concentration in $\mathrm{g} / \mathrm{ml}$, and 3.47 is equivalent to the concentration of $\mathrm{Fe}$ in $\mathrm{Hb}(\mathrm{mg} / \mathrm{g})$.

The calculation is somewhat complicated by the fact that the ${ }^{58} \mathrm{Fe}$ label contained a small amount of ${ }^{57} \mathrm{Fe}$ and the ${ }^{57} \mathrm{Fe}$ label contained a small amount of ${ }^{58} \mathrm{Fe}$. Absorption of ${ }^{57} \mathrm{Fe}$ was calculated assuming that the contribution of absorbed ${ }^{57} \mathrm{Fe}$ from the ${ }^{58} \mathrm{Fe}$ label was negligible. Furthermore, $90 \%$ of absorbed Fe was assumed to be incorporated into erythrocytes (Rios et al. 1975):

$$
{ }^{57} \mathrm{Fe}_{\text {(absorbed) }} \%=\frac{{ }^{57} \mathrm{Fe}_{(\text {inc })}}{{ }^{57} \mathrm{Fe}_{(\text {dose })}} \times \frac{100}{90} \times 100,
$$

where ${ }^{57} \mathrm{Fe}_{(\text {inc) }}$ and ${ }^{57} \mathrm{Fe}_{\text {(dose) }}$ are given in $\mathrm{mg}$. The amount of ${ }^{58} \mathrm{Fe}$ coming from the ${ }^{57} \mathrm{Fe}$ label and incorporated into erythrocytes was then calculated assuming identical absorption for the ${ }^{58} \mathrm{Fe}$ and the ${ }^{57} \mathrm{Fe}$ present in the ${ }^{57} \mathrm{Fe}$ label:

$$
{ }^{58} \mathrm{Fe}_{(\text {ine) }}{ }^{* *}={ }^{58} \mathrm{Fe}^{*} \times \frac{{ }^{57} \mathrm{Fe}_{(\text {absorbed) }} \%}{100} \times \frac{90}{100}
$$

where ${ }^{58} \mathrm{Fe}_{(\text {inc) }}{ }^{* *}$ is the amount of ${ }^{58} \mathrm{Fe}$ incorporated $(\mathrm{mg})$ into erythrocytes (from ${ }^{57} \mathrm{Fe}$ label) and ${ }^{58} \mathrm{Fe}^{*}$ is the amount of ${ }^{58} \mathrm{Fe}$ administered with ${ }^{57} \mathrm{Fe}$ label (mg).

The amount of incorporated ${ }^{58} \mathrm{Fe}$ which came from the ${ }^{57} \mathrm{Fe}$ label was then subtracted from the total amount of incorporated ${ }^{58} \mathrm{Fe}$ :

$$
{ }^{58} \mathrm{Fe}_{(\text {inc/corr) }}=\operatorname{total}{ }^{58} \mathrm{Fe}_{(\text {inc) }}-{ }^{58} \mathrm{Fe}_{(\mathrm{inc})}{ }^{* *} .
$$

${ }^{58} \mathrm{Fe}$ absorption was thereafter calculated as for ${ }^{57} \mathrm{Fe}$ :

$$
{ }^{58} \mathrm{Fe}_{\text {(absorbed) }} \%=\frac{{ }^{58} \mathrm{Fe}_{(\text {inc/corr })}}{{ }^{58} \mathrm{Fe}_{(\text {dose })}} \times \frac{100}{90} \times 100
$$

where ${ }^{58} \mathrm{Fe}_{(\text {inc/corr })}$ and ${ }^{58} \mathrm{Fe}_{(\text {dose })}$ are given in mg. Student's paired $t$ test was used to evaluate whether there was a significant difference for the Fe absorption obtained, using the two isotopes.

\section{RESULTS}

Mass spectrometric measurements

The results for mass spectrometric analysis of the enriched standards are given in Table 2 . The average difference between the expected and measured ratios for ${ }^{57} \mathrm{Fe}$ and ${ }^{58} \mathrm{Fe}$ was within one standard deviation for ten repeated measurements of the natural ratio. This indicated that there was no systematic error in the mass spectrometric measurements.

An external precision of 0.6 and $1.1 \%$ was obtained for $\mathrm{Fe}$ from the Merck standard for the isotope ratios ${ }^{57} \mathrm{Fe}:{ }^{56} \mathrm{Fe}$ and ${ }^{58} \mathrm{Fe}:{ }^{56} \mathrm{Fe}(n 10)$. Fe isolated from animal blood was measured with an external precision of 0.7 and $1.6 \%(n 7)$. Careful control of the amount of silica gel on the filament and of the filament temperature was found to be essential to achieve high reproducibility. No fractionation correction was applied to the measured ratios as they were sufficiently stable and close to the reference natural values. The natural isotope abundances used for the absorption calculations were derived from isotope ratios 
Table 2. Isotopic ratios of enriched standards with different degrees of enrichment; expected values compared with measured ratios and the difference between the two values

\begin{tabular}{|c|c|c|c|c|}
\hline & \multirow[b]{2}{*}{ Enrichment (\%) } & \multicolumn{3}{|c|}{ Isotopic ratio } \\
\hline & & Expected & Measured & Difference $(\%)$ \\
\hline & & & ${ }^{57} \mathrm{Fe}:{ }^{56} \mathrm{Fe}$ & \\
\hline \multirow[t]{3}{*}{$\begin{array}{l}\text { Fe enriched } \\
\text { with }{ }^{57} \mathrm{Fe}\end{array}$} & $\begin{array}{r}0 \\
3.05 \\
4.99 \\
9.98 \\
36.98\end{array}$ & $\begin{array}{l}0.02357 \\
0.02401 \\
0.02515 \\
0.03133\end{array}$ & $\begin{array}{l}0.02287 \\
0.02349 \\
0.02408 \\
0.02518 \\
0.03148\end{array}$ & $\begin{array}{l}-0.34 \\
+0.29 \\
+0.12 \\
+0.48\end{array}$ \\
\hline & Mean & & & $+0 \cdot 14$ \\
\hline & & & ${ }^{58} \mathrm{Fe}:{ }^{56} \mathrm{Fe}$ & \\
\hline \multirow[t]{2}{*}{$\begin{array}{l}\text { Fe enriched } \\
\text { with }{ }^{58} \mathrm{Fe}\end{array}$} & $\begin{array}{c}0 \\
10 \cdot 12 \\
29 \cdot 95 \\
44 \cdot 36 \\
299 \cdot 7\end{array}$ & $\begin{array}{l}0.003309 \\
0.003905 \\
0.004338 \\
0.012007\end{array}$ & $\begin{array}{l}0.003005 \\
0.003333 \\
0.003913 \\
0.004329 \\
0.011947\end{array}$ & $\begin{array}{l}+0.73 \\
+0.20 \\
-0.21 \\
-0.50\end{array}$ \\
\hline & Mean & & & +0.06 \\
\hline
\end{tabular}

Table 3. Measured isotopic abundances of Fe isotopes in enriched labels

\begin{tabular}{ccc}
\hline \hline Isotopic abundance (A) & ${ }^{57} \mathrm{Fe} \mathrm{label} \mathrm{(atomic} \mathrm{\% )}$ & ${ }^{58} \mathrm{Fe}$ label* (atomic \%) \\
\hline $\mathrm{A}_{54}$ & - & $4 \cdot 331$ \\
$\mathrm{~A}_{56}$ & $2 \cdot 335$ & $70 \cdot 652$ \\
$\mathrm{~A}_{57}$ & $95 \cdot 30$ & $2 \cdot 529$ \\
$\mathrm{~A}_{58}$ & $2 \cdot 37$ & 22.488 \\
Atomic mass (Da) & 56.939 & 56.323 \\
\hline
\end{tabular}

${ }^{*}{ }^{58} \mathrm{Fe}$ was diluted as described on page 412 .

measured in animal blood. The following values were obtained (atomic $\%$ ): ${ }^{54} \mathrm{Fe}, 5 \cdot 83$; ${ }^{56} \mathrm{Fe}, 91 \cdot 79 ;{ }^{57} \mathrm{Fe}, 2 \cdot 10 ;{ }^{58} \mathrm{Fe}, 0 \cdot 277$. The isotope abundances determined for the ${ }^{57} \mathrm{Fe}$ and the ${ }^{58} \mathrm{Fe}$ labels are given in Table 3.

\section{Fe absorption measurements}

The intake of each isotope (Table 4) was calculated from the amounts of ingested formula. Of the offered volume of formula, 73-99\% of that labelled with ${ }^{57} \mathrm{Fe}$ and $83-99 \%$ of that labelled with ${ }^{58} \mathrm{Fe}$ was consumed by the infants. The amount of ${ }^{57} \mathrm{Fe}$ ingested with the ${ }^{58} \mathrm{Fe}$ label represented $2 \cdot 4-3.6 \%$ of the ${ }^{57} \mathrm{Fe}$ ingested with the ${ }^{57} \mathrm{Fe}$ label. The ${ }^{58} \mathrm{Fe}$ ingested with the ${ }^{57} \mathrm{Fe}$ label represented $7 \cdot 8-11.4 \%$ of the ${ }^{58} \mathrm{Fe}$ in the ${ }^{58} \mathrm{Fe}$ label. As it was not possible to correct for cross-contaminations for both isotopes, the correction was made for the ${ }^{58} \mathrm{Fe}$ isotope, as the contribution of ${ }^{58} \mathrm{Fe}$ from the ${ }^{57} \mathrm{Fe}$ label represented a larger fraction than vice versa.

The $\mathrm{Fe}$ isotope ratios measured after incorporation of the absorbed label into the erythrocytes are shown in Table 5. The mean value of the analysis of blood from six infants 
Table 4. Intakes of ${ }^{57} \mathrm{Fe}$ and ${ }^{58} \mathrm{Fe}$, calculated from the amount of ingested formula for each infant

\begin{tabular}{|c|c|c|c|c|}
\hline \multirow[b]{2}{*}{ Subject } & \multicolumn{2}{|c|}{ Total ${ }^{57} \mathrm{Fe}$ ingested from } & \multicolumn{2}{|c|}{ Total ${ }^{58} \mathrm{Fe}$ ingested from } \\
\hline & $\begin{array}{l}{ }^{57} \mathrm{Fe} \text { labelled meal } \\
\text { (mg) }\end{array}$ & $\begin{array}{l}{ }_{(\mathrm{mg})}^{58} \mathrm{Fe} \text { labelled meal } \\
{ }^{5}\end{array}$ & $\begin{array}{l}{ }^{58} \mathrm{Fe} \text { labelled meal } \\
(\mathrm{mg})\end{array}$ & $\begin{array}{l}{ }^{57} \mathrm{Fe} \text { labelled meal } \\
(\mathrm{mg})\end{array}$ \\
\hline A & $4 \cdot 468$ & $0 \cdot 109$ & 0.992 & 0.113 \\
\hline B & $4 \cdot 602$ & $0 \cdot 124$ & $1 \cdot 130$ & 0.117 \\
\hline $\mathrm{C}$ & $4 \cdot 766$ & $0 \cdot 129$ & $1 \cdot 181$ & $0 \cdot 120$ \\
\hline D & $4 \cdot 724$ & $0 \cdot 125$ & $1 \cdot 137$ & 0.120 \\
\hline $\mathrm{E}$ & 4.754 & $0 \cdot 130$ & $1 \cdot 181$ & $0 \cdot 120$ \\
\hline $\mathrm{F}$ & $4 \cdot 765$ & $0 \cdot 126$ & $1 \cdot 152$ & 0.121 \\
\hline $\mathrm{G}$ & $4 \cdot 765$ & 0.128 & $1 \cdot 166$ & 0.121 \\
\hline $\mathrm{H}$ & $4 \cdot 351$ & 0.127 & $1 \cdot 159$ & 0.110 \\
\hline I & 3.542 & 0.127 & $1 \cdot 161$ & 0.090 \\
\hline
\end{tabular}

Table 5. Fe isotope ratios measured in erythrocytes of infants 2 weeks after administration of ${ }^{57} \mathrm{Fe}$ and ${ }^{58} \mathrm{Fe}$ labels in the diet*

(Mean values and standard deviations from thirty-three measurements of duplicate samples)

\begin{tabular}{|c|c|c|c|c|}
\hline \multirow[b]{2}{*}{ Subject } & \multicolumn{2}{|c|}{${ }^{57} \mathrm{Fe}:{ }^{56} \mathrm{Fe}$} & \multicolumn{2}{|c|}{${ }^{58} \mathrm{Fe}:{ }^{56} \mathrm{Fe}$} \\
\hline & Mean & SD & Mean & SD \\
\hline \multirow[t]{2}{*}{ A } & 0.024346 & 0.000061 & 0.003399 & 0.000014 \\
\hline & 0.024095 & 0.000061 & 0.003348 & 0.000018 \\
\hline \multirow[t]{2}{*}{ B } & 0.025000 & 0.000050 & 0.003575 & 0.000012 \\
\hline & 0.024865 & 0.000030 & 0.003545 & 0.000010 \\
\hline \multirow[t]{2}{*}{$\mathrm{C}$} & 0.024549 & 0.000050 & 0.003351 & 0.000006 \\
\hline & 0.024599 & 0.000055 & 0.003354 & 0.000016 \\
\hline \multirow[t]{2}{*}{$\mathrm{D}$} & 0.024803 & 0.000058 & 0.003671 & 0.000012 \\
\hline & 0.025134 & 0.000052 & 0.003739 & 0.000014 \\
\hline \multirow[t]{2}{*}{$E$} & 0.022938 & 0.000048 & 0.003080 & 0.000008 \\
\hline & 0.023089 & 0.000052 & 0.003089 & 0.000012 \\
\hline \multirow[t]{2}{*}{$\mathrm{F}$} & 0.022715 & 0.000130 & 0.003090 & 0.000020 \\
\hline & 0.022892 & 0.000085 & 0.003110 & 0.000011 \\
\hline \multirow[t]{2}{*}{$\mathrm{G}$} & 0.023682 & 0.000097 & 0.003230 & 0.000012 \\
\hline & 0.023942 & 0.000050 & 0.003285 & 0.000008 \\
\hline \multirow[t]{2}{*}{$\mathbf{H}$} & 0.025146 & 0.000038 & 0.003744 & 0.000009 \\
\hline & 0.025276 & 0.000064 & 0.003785 & 0.000012 \\
\hline \multirow[t]{2}{*}{ I } & 0.023654 & 0.000054 & 0.003296 & 0.000007 \\
\hline & 0.023930 & 0.000095 & 0.003331 & 0.000018 \\
\hline
\end{tabular}

${ }^{*}$ Mean base line ratios for six infants on day 1 were 0.02224 (SD 0.00011 ) for ${ }^{57} \mathrm{Fe}:{ }^{56} \mathrm{Fe}$ and 0.002923 (SD 0.000037) for ${ }^{58} \mathrm{Fe}:{ }^{56} \mathrm{Fe}$.

on day 1 was used as a baseline value for all subjects. External precision obtained was $0.5 \%$ for the ${ }^{57} \mathrm{Fe}:{ }^{56} \mathrm{Fe}$ ratio and $1 \cdot 3 \%$ for the ${ }^{58} \mathrm{Fe}:{ }^{56} \mathrm{Fe}$ ratio $(n 6)$. Consequently, the smallest enrichment that could be resolved was $1.5 \%$ for the ${ }^{57} \mathrm{Fe}:{ }^{56} \mathrm{Fe}$ ratio and $3.9 \%$ for the ${ }^{58} \mathrm{Fe}:{ }^{56} \mathrm{Fe}$ ratio respectively $(3 \times \mathrm{SD})$. Enriched blood samples were analysed in duplicate. Average difference between the duplicates was $0.7 \%$ for ${ }^{57} \mathrm{Fe}:{ }^{56} \mathrm{Fe}$ and $1.0 \%$ for ${ }^{58} \mathrm{Fe}:{ }^{56} \mathrm{Fe}$, with ranges of $0 \cdot 4-1 \cdot 3$ and $0 \cdot 1-1 \cdot 8 \%$ respectively. 
Table 6. Amounts of ${ }^{57} \mathrm{Fe}$ and ${ }^{58} \mathrm{Fe}$ incorporated into erythrocytes on day 18 and calculated fractional absorption of the isotopes

\begin{tabular}{|c|c|c|c|c|}
\hline \multirow[b]{2}{*}{ Subject } & \multicolumn{2}{|c|}{ Incorporated label (mg) } & \multicolumn{2}{|c|}{ Absorbed label ( $\%$ of dose) } \\
\hline & ${ }^{57} \mathrm{Fe}^{*}$ & ${ }^{58} \mathrm{Fe} \dagger$ & ${ }^{57} \mathrm{Fe}$ & ${ }^{58} \mathrm{Fe}$ \\
\hline A & $0 \cdot 3489$ & 0.0783 & 8.68 & $8 \cdot 77$ \\
\hline B & $0 \cdot 4968$ & $0 \cdot 1133$ & $12 \cdot 00$ & $11 \cdot 14$ \\
\hline $\mathrm{C}$ & $0 \cdot 3572$ & 0.0624 & 8.33 & 5.87 \\
\hline $\mathrm{D}$ & 0.4460 & $0 \cdot 1265$ & $10 \cdot 49$ & $12 \cdot 21$ \\
\hline $\mathrm{E}$ & $0 \cdot 1153$ & 0.0267 & $2 \cdot 70$ & $2 \cdot 51$ \\
\hline $\mathrm{F}$ & 0.0786 & 0.0309 & 1.83 & $2 \cdot 98$ \\
\hline $\mathrm{G}$ & 0.2703 & 0.0574 & $6 \cdot 30$ & $5 \cdot 47$ \\
\hline $\mathrm{H}$ & 0.5218 & $0 \cdot 1454$ & $13 \cdot 33$ & 13.94 \\
\hline I & $0 \cdot 2343$ & 0.0601 & $7 \cdot 35$ & $5 \cdot 75$ \\
\hline \multicolumn{3}{|c|}{ Mean $\ddagger$} & $6 \cdot 72$ & $6 \cdot 58$ \\
\hline \multicolumn{3}{|c|}{$+1 \mathrm{sD}$} & $13 \cdot 20$ & $12 \cdot 04$ \\
\hline \multicolumn{3}{|c|}{$-1 \mathbf{S D}$} & $3 \cdot 42$ & $3 \cdot 59$ \\
\hline
\end{tabular}

The incorporated amounts of ${ }^{57} \mathrm{Fe}$ and ${ }^{58} \mathrm{Fe}$ on day 18 and the calculated fractional absorption of the administered labels are presented in Table 6 . The mean of the two independent isotope ratio determinations was used in the calculations. The absorption of the ${ }^{57} \mathrm{Fe}$ label was in the range $1.83-13.33 \%$ with a geometric mean of $6.72 \%$. For ${ }^{58} \mathrm{Fe}$, absorption values of $2.51-13.94 \%$ were found, with a geometric mean of $6.58 \%$. No statistically significant difference was found between the absorption values of the two isotopes (Student's paired $t$ test).

\section{DISCUSSION}

The results from the present study demonstrate that it is possible to use a double stable isotope technique with ${ }^{57} \mathrm{Fe}$ and ${ }^{58} \mathrm{Fe}$ as labels to measure $\mathrm{Fe}$ absorption in infants. The mean geometric $\mathrm{Fe}$ absorption found in this study, 6.71 and $6.58 \%$ for ${ }^{57} \mathrm{Fe}$ and ${ }^{58} \mathrm{Fe}$ respectively (range 1.83-13.94\%), is similar to earlier published results of Fe absorption by infants from an infant formula containing ascorbic acid.

Rios et al. (1975) measured Fe absorption in infants 4-7 months old from two infant formulas based on cow's milk and one based on soya bean containing 16-18 mg Fe (as $\left.\mathrm{FeSO}_{4}\right) / 1$. Radioactive $\mathrm{Fe}\left({ }^{55} \mathrm{Fe}\right)$ was used to label the feeds $(120 \mathrm{ml})$ and $\mathrm{Fe}$ absorption was determined by measuring the radioactivity in the circulating erythrocytes $14 \mathrm{~d}$ after administration. No significant difference was observed in $\mathrm{Fe}$ absorption from the different formulas; geometric mean absorption was 3.9 and $3.4 \%$ from the milk formula and $5.4 \%$ from the soya-bean formula. A wide variation in $\mathrm{Fe}$ absorption was observed between different infants; $0 \cdot 7-23 \cdot 1 \%$ of the dose was absorbed.

In the study by Stekel et al. (1986) using the same radioisotope technique, Fe absorption from several different $\mathrm{FeSO}_{4}$-fortified cow's milk-based formulas $(10-19 \mathrm{mg} \mathrm{Fe} / \mathrm{l})$ was measured in children aged 5-18 months. The geometric mean $\mathrm{Fe}$ absorption varied between 2.9 and $5.1 \%$ for formulas without ascorbic acid, while the addition of ascorbic acid $(100-800 \mathrm{mg} / \mathrm{l})$ increased the mean absorption of $\mathrm{Fe}$ to $5 \cdot 9-11 \cdot 3 \%$. No individual $\mathrm{Fe}$ 
absorption values are given in the article, but the range of $\mathrm{Fe}$ absorption for each group clearly shows the relatively large variation in Fe absorption between subjects.

These data taken together thus clearly demonstrate the need for a double-isotope method making it possible to use each infant as his or her own control when identifying dietary factors influencing Fe absorption.

\section{Analytical methodology}

External precision for measured $\mathrm{Fe}$ isotope ratios from standards and samples was in the range $0 \cdot 5-0 \cdot 7 \%$ for ${ }^{57} \mathrm{Fe}:{ }^{56} \mathrm{Fe}$ and $1 \cdot 1-1 \cdot 6 \%$ for ${ }^{58} \mathrm{Fe}:{ }^{56} \mathrm{Fe}$. This precision was significantly better than the values published by Götz \& Heumann (1988) who obtained an external precision of $1.2 \%$ for ${ }^{57} \mathrm{Fe}:{ }^{56} \mathrm{Fe}$ and $5 \% 3 \%$ for ${ }^{58} \mathrm{Fe}:{ }^{56} \mathrm{Fe}$ with a quadrupole mass spectrometer, similar to the one we used, while Eagles et al. (1985) reported an external precision of $1.7 \%$ for the ${ }^{58} \mathrm{Fe}:{ }^{56} \mathrm{Fe}$ ratio using fast atom bombardment mass spectrometry (FAB-MS). Fomon et al. (1988) measured Fe absorption in infants with ${ }^{58} \mathrm{Fe}$ as a single label using inductively coupled plasma mass spectrometry (ICP-MS). These authors reported an external precision of $0 \cdot 3-1.6 \%$ for the ${ }^{57} \mathrm{Fe}:{ }^{58} \mathrm{Fe}$ ratio which was chosen because it gave a better precision than the ${ }^{58} \mathrm{Fe}:{ }^{56} \mathrm{Fe}$ ratio. Using our technique, this ratio was measured with an external precision of $0 \cdot 6 \%$.

In the study by Fomon et al. (1988) the coefficient of variation (CV) for ${ }^{58} \mathrm{Fe}$ absorption measurement was determined by analysis of three blood samples taken at 4,8 and 12 weeks after administration of the label, assuming no change in the isotopic composition of $\mathrm{Fe}$ in the erythrocytes during this period of time. The resulting CV was between 1.0 and $30.5 \%$ depending on the amount of label absorbed. The smallest error was found for the highest Fe absorption (16.0\%) and the largest error for the lowest absorption $(3 \cdot 3 \%$.). In their study it was also shown that measured errors agreed well with the expected errors calculated based on the uncertainties in the determination of the baseline and enriched isotope ratios. Using their approach and the variation of our isotope ratio measurements we obtained CV of 5.2 and $5.6 \%\left({ }^{57} \mathrm{Fe}\right.$ absorption $13.3 \%$ and ${ }^{58} \mathrm{Fe}$ absorption $\left.13.9 \%\right)$ respectively. For the lowest measured absorption of $1.83 \%$ for ${ }^{57} \mathrm{Fe}$ and $2.51 \%$ for ${ }^{58} \mathrm{Fe}$ we obtained coefficients of variation of 30.4 and $23.3 \%$ respectively. These values are thus in the same order of magnitude as the values reported by Fomon et al. (1988). Furthermore, the values reflect the capability of ICP-MS and TIMS using a quadrupole mass analyser to measure the ${ }^{57} \mathrm{Fe}:{ }^{58} \mathrm{Fe}$ ratio and the ${ }^{58} \mathrm{Fe}:{ }^{56} \mathrm{Fe}$ ratio with approximately the same precision. However, if ICP-MS were to be used in conjunction with the double-isotope technique, the ${ }^{58} \mathrm{Fe}$ would need to be measured relative to either ${ }^{54} \mathrm{Fe}$ or ${ }^{56} \mathrm{Fe}$ as the reference isotope, and it is not certain whether the ICP-MS technique could measure these ratios with sufficient precision when using commercially available instruments.

As isotopically pure labels are not available, the measured absorption values had to be corrected for cross-contamination of $\mathrm{Fe}$ isotopes. The correction was done for ${ }^{58} \mathrm{Fe}$. No correction was made for ${ }^{57} \mathrm{Fe}$ absorbed from the meal labelled with ${ }^{58} \mathrm{Fe}$ which resulted in a slight overestimate of the ${ }^{57} \mathrm{Fe}$ absorption (equation 4). This can be further demonstrated by making the hypothetical calculations for a study in which the first meal is labelled with $5 \mathrm{mg}{ }^{57} \mathrm{Fe}$ and the second meal with a ${ }^{58} \mathrm{Fe}$ label containing $0 \cdot 1 \mathrm{mg}{ }^{57} \mathrm{Fe}$. Assuming that the Fe absorption from the two meals is identical at $8 \%, 0.4 \mathrm{mg}$ of ${ }^{57} \mathrm{Fe}$ will be absorbed from meal 1 and $0.008 \mathrm{mg}$ from meal 2. Absorption from meal 1 , measured from total ${ }^{57} \mathrm{Fe}$ incorporated into haemoglobin, will be 8.16 rather than $8 \%$, resulting in an error of $2 \%$. If the absorption of Fe from meal 2 labelled with ${ }^{58} \mathrm{Fe}$ was $16 \%$, and that from meal 1 remained at $8 \%$, then the measured absorption of the ${ }^{57} \mathrm{Fe}$ label would be $8 \cdot 32 \%$, giving an error of $4 \%$. In the present study a correction was made for the ${ }^{58} \mathrm{Fe}$ present in the ${ }^{57} \mathrm{Fe}$ tracer. However, as the uncorrected ${ }^{57} \mathrm{Fe}$ absorption was used to make this correction, a 
small error was again introduced. This error is usually less than $1 \%$ and negligible compared with the much larger errors associated with the mass spectrometric measurement itself.

The precision of the absorption measurements and the lowest absorption that can be detected are determined by the precision of the mass spectrometric measurements. To obtain a better precision with the thermal ionization quadrupole mass spectrometer the ionization efficiency for Fe must be increased so that higher ion currents are obtained and the Faraday detector can be used. At the present time, however, no other technique is known to give higher ion yields than the mixture of silica gel and Al already used in the present study. With a high sensitivity magnetic-sector mass spectrometer equipped with a multicollector system for simultaneous detection of isotopes, Fe isotope ratios can be measured with a precision approximately two to five times better than with a quadruple instrument (Turnlund \& Keyes, 1990). The lowest Fe absorption possible to measure can be calculated using the smallest enrichments, relative to the baseline ratio, which can be resolved. In our study the detection limit for shifts of the ${ }^{57} \mathrm{Fe}:{ }^{56} \mathrm{Fe}$ ratio was $1.5 \%$ and for the ${ }^{58} \mathrm{Fe}:{ }^{56} \mathrm{Fe}$ ratio $3.9 \%$. In an infant weighing $7 \mathrm{~kg}$ (with $173.5 \mathrm{mg}$ circulating $\mathrm{Fe}$ ) the resulting detection limit for ${ }^{57} \mathrm{Fe}$ absorption would be $1.2 \%$ and for ${ }^{58} \mathrm{Fe} 1.8 \%$. By improving the precision of the isotope ratio measurements to $0 \cdot 1 \%$ for ${ }^{57} \mathrm{Fe}:{ }^{56} \mathrm{Fe}$ and $0 \cdot 2 \%$ for ${ }^{58} \mathrm{Fe}:{ }^{56} \mathrm{Fe}$, by using a magnetic sector mass spectrometer, the detection limits for $\mathrm{Fe}$ absorption could be lowered to 0.24 and $0.27 \%$ respectively.

Improved precision of the isotope ratio measurements also increases the precision of the absorption measurement. This is especially important for studies where very low absorption values are to be expected. For example, for the lowest measured absorptions of $1.83 \%$ $\left({ }^{57} \mathrm{Fe}\right.$ ) and $2.51 \%\left({ }^{58} \mathrm{Fe}\right)$ the calculated $\mathrm{CV}$ were 30.4 and $23.3 \%$ respectively, while with the improved precision these values would be reduced to $9 \cdot 2 \%$ for ${ }^{57} \mathrm{Fe}$ and $5 \cdot 3 \%$ for ${ }^{58} \mathrm{Fe}$. Another possible way to increase the precision of the double-isotope technique would be to give more label in order to increase the isotope ratio shifts. The present level of label, $5 \mathrm{mg}{ }^{57} \mathrm{Fe}$ and $1.2 \mathrm{mg}{ }^{58} \mathrm{Fe}$, was given over two meals each consisting of $210 \mathrm{ml}$ formula. The two options available when trying to increase the isotope ratio shift would be either to increase the number of labelled meals or to increase the amount of isotope per meal. Neither of these possibilities was practically feasible since the amount of added Fe per meal $(2.5 \mathrm{mg}$ ) was dictated by the normal Fe concentration of infant formula, and increasing the number of meals would have resulted in a more laborious study design. Furthermore, stable isotopes of $\mathrm{Fe}$ are expensive, approximately 30 Swiss francs per $\mathrm{mg}{ }^{57} \mathrm{Fe}$ and 350 Swiss francs per $m g{ }^{58} \mathrm{Fe}$, and any increase of the dose would further increase the cost of the studies. Total cost of isotopes for a study including ten infants is approximately 5700 Swiss francs.

\section{Study design}

The design of the present study, using two administrations of each labelled test meal, was chosen to make it possible to keep the Fe concentration in the formula at the commercial level used in the US $(12 \mathrm{mg} / \mathrm{l})$ and to avoid the practical problems involved in administrations of large volumes of formula to young children. A volume of $210 \mathrm{ml}$ of labelled formula was given at one feed on each of 4 consecutive days. An infant can consume this volume within a short time thus making the procedure of administration as convenient as possible for the mother and child. If a lower total Fe concentration were to be used in the formulas studied it would be necessary to give a larger volume per feed or to include a third administration of each test meal which would result in a more complicated study design when non-hospitalized infants are studied.

With the present double-isotope study design only two blood samples (approximately 
$1 \mathrm{ml}$ each) are needed to determine Fe absorption from two different test meals. This is an advantage compared with repeated administrations of labelled feeds with $14 \mathrm{~d}$ in between when a total of three blood samples would have to be drawn. In studies of infants it is a major concern to keep the number of blood samples, as well as the blood volume drawn, as low as possible.

Each infant's blood volume was calculated at the time of the second blood sample by multiplying body weight $(\mathrm{kg})$ by a factor $(65 \mathrm{ml} / \mathrm{kg})$. This factor has been used previously by Fomon et al. (1988) for calculations of blood volume in infants. The original data were reported by Bratteby (1968); in this study of erythro-kinetics the blood volume of six infants (113-138 d old) varied between 62.9 and $68.6 \mathrm{ml} / \mathrm{kg}$ body weight, resulting in a mean value of $65 \mathrm{ml} / \mathrm{kg}$. In older children, or children with specific physiological conditions, another factor would be necessary. Direct measurement of blood volume is difficult in non-hospitalized infants due to ethical and practical considerations. Using our double stable isotope technique the measurement of Fe absorption from two test meals can be made with a very short time lapse between administrations and changes in blood volume will have a minimal influence on the results.

In our study, $90 \%$ of the absorbed $\mathrm{Fe}$ was assumed to be incorporated into erythrocytes $14 \mathrm{~d}$ after intake. This value has previously been used by Rios et al. (1975). Very little information is available concerning the percentage of absorbed $\mathrm{Fe}$ that is incorporated into erythrocytes. Garby et al. (1963) found that about $85 \%$ of an injected dose of ${ }^{59} \mathrm{Fe}$ was present in erythrocytes $9-14 \mathrm{~d}$ post-injection in three infants 81 to $129 \mathrm{~d}$ old. No data are available for older infants and we therefore agree with Fomon et al. (1988) that there is no reason to doubt the assumption by Rios et al. that $90 \%$ of absorbed iron is incorporated into erythrocytes.

As discussed above, the total amount of the Fe labels administered was $5 \mathrm{mg}{ }^{57} \mathrm{Fe}$ and $1.2 \mathrm{mg}{ }^{58} \mathrm{Fe}$. These rather high amounts of isotopes are necessary to give the required precision for measuring the isotope shifts in infants with widely different capacities for $\mathrm{Fe}$ absorption. All test meals studied will consequently contain an added quantity of Fe which is not negligible. This is not a major concern when investigating the absorption of fortification $\mathrm{Fe}$, but could lead to difficulties in the interpretation of $\mathrm{Fe}$ absorption from home-made weaning foods that are not normally Fe-fortified (e.g. vegetable purée, scrambled eggs, etc.). The increase of total $\mathrm{Fe}$ by the addition of stable isotopes is therefore a limitation compared with studies using radioactive isotopes where the total content of $\mathrm{Fe}$ is not increased by the addition of the label. The measurement of native food Fe absorption is much more complicated when using a stable isotope technique and would require incorporation of the stable isotope(s) in vivo into the food followed by administration over several meals or several days. The use of ${ }^{58} \mathrm{Fe}$ as a label followed by analysis using a magnetic sector mass spectrometer would present the best possibility for such a study as with its higher precision it would permit the use of a smaller quantity of isotope over a short time period. However, in studies of infants a safe method which does not involve any risks associated with radiation is a necessity. The limitations of the stable isotope technique must therefore be carefully considered when designing studies of $\mathrm{Fe}$ absorption and the increased Fe content taken into account when interpreting the results.

The stable isotope technique for the study of $\mathrm{Fe}$ absorption from foods by measuring enrichment of erythrocytes is limited to studies in infants because of the considerable amounts of isotopes that need to be administered when studying adults. To enrich the haemoglobin in a $70 \mathrm{~kg}$ adult to the same extent as a $7 \mathrm{~kg}$ infant would require about ten times more isotope to be administered. These amounts of $\mathrm{Fe}$ are of such a magnitude compared with the normal level of $\mathrm{Fe}$ in diets consumed by healthy adults that they have to be regarded as Fe-supplements and not food Fe-fortification if given over only $1 \mathrm{~d}$. It 
would theoretically be possible to spread the intake of the labelled test meals over a longer period of time (several days or weeks) to overcome this problem, but the cost of the stable isotopes would be excessively high, approximately 57000 Swiss francs for ten adult subjects.

A further improvement of the double-isotope technique would be to include a reference dose of a third isotope of $\mathrm{Fe}$, i.e. ${ }^{54} \mathrm{Fe}$. The inclusion of a reference dose would provide information which would make it possible to standardize the individual values of $\mathrm{Fe}$ absorption, e.g. to $40 \%$ absorption of the reference dose for comparisons between different groups of subjects. This approach is used to compare Fe absorption using radioactive $\mathrm{Fe}$ in different studies in adults (Cook et al. 1972).

In conclusion, a double-isotope technique to measure $\mathrm{Fe}$ absorption in infants using stable isotopes has been developed. Two isotopes, ${ }^{57} \mathrm{Fe}$ and ${ }^{58} \mathrm{Fe}$, were used to label test meals given on consecutive days and $\mathrm{Fe}$ absorption was calculated based on the incorporation of ${ }^{57} \mathrm{Fe}$ and ${ }^{58} \mathrm{Fe}$ in erythrocytes $14 \mathrm{~d}$ after administration. Isotope ratios were measured by TIMS. By this technique paired comparisons of $\mathrm{Fe}$ absorption from two different test meals can be obtained and studies of dietary factors such as phytic acid, ascorbic acid and $\mathrm{Ca}$ which influence $\mathrm{Fe}$ absorption in infants can be made.

\section{REFERENCES}

Barnes, I. L., Murphy, T. J. \& Shields, W. R. (1973). Lead separation by anodic decomposition and isotope ratio mass spectrometry of microgram and smaller samples. Analytical Chemistry 45, 1881-1884.

Beer, B. \& Heumann, K. G. (1992). Trace analysis of U, Th and other heavy metals in high purity aluminium with isotope dilution mass spectrometry. Fresenius Zeitschrift für Analytische Chemie 343, 741-745.

Bratteby, L. E. (1968). Studies on erythro-kinetics in infancy. XI. The change in the circulating red cell volume during the first five months of life. Acta Paediatrica Scandinavica 57, 215-224.

Cook, J. D., Layrisse, M., Martinez-Torres, C., Walker, R., Monsen, E. \& Finch, C. A. (1972). Food iron absorption measured by an extrinsic tag. Journal of Clinical Investigation 51, 805-815.

Dallman, P. R., Siimes, M. A. \& Stekel, A. (1980). Iron deficiency in infancy and childhood. American Journal of Clinical Nutrition 33, 86-118.

De Bièvre, P. \& Barnes, J. L. (1985). Table of the isotopic composition of the elements as determined by mass spectrometry. International Journal of Mass Spectrometry and Ion Processes 65, 211-230.

Dixon, W. J. \& Massey, F. J. (1969). Introduction to Statistical Analysis, pp. 328-330. New York: McGraw Hill.

Eagles, J., Fairweather-Tait, S. J. \& Self, R. (1985). Stable isotope ratio mass spectrometry for iron bioavailability studies. Analytical Chemistry 57, 469471.

Fasset, J. D., Powell, L. J. \& Moore, L. J. (1984). Determination of iron in serum and water by resonance ionisation isotope dilution mass spectrometry. Analytical Chemistry 56, 2228-2233.

Fomon, S. J., Janghorbani, M., Ting, B. T. G., Ziegler, E. E., Rogers, R. R., Nelson, S. E., Ostergaard, L. S. \& Edwards, B. B. (1988). Erythrocyte incorporation of ingested 58-iron by infants. Pediatric Research 24, $20-24$.

Fomon, S. J., Ziegler, E. E., Rogers, R. R., Nelson, S. E., Edwards, B. E., Guy, P. G., Erve, C. J. \& Janghorbani, M. (1989). Iron absorption from infant foods. Pediatric Research 26, 250-254.

Garby, L., Sjolin, S. \& Vuille, J. C. (1963). Studies on erythro-kinetics in infancy. III. Disappearance from plasma and red cell uptake of radioactive iron injected intravenously. Acta Paediatrica 52, 537-553.

Götz, A. \& Heumann, K. G. (1987). Heavy metal trace determination with a compact thermal ionisation quadrupole mass spectrometer. Part 2. Analysis of food samples. Fresenius Zeitschrift für Analytische Chemie 326, $118-122$.

Götz, A. \& Heumann, K. G. (1988). Iron isotope ratio measurements with the thermal ionisation technique using a compact quadrupole mass spectrometer. International Journal of Mass Spectrometry and Ion Processes $\mathbf{8 3}$, 319-330.

Hallberg, L. \& Björn-Rasmussen, E. (1972). Determination of iron absorption from whole diet. A new two-pool model using two radioiron isotopes given as haem and non-haem iron. Scandinavian Journal of Haematology 9, 193-197.

Janghorbani, M. \& Ting, B. T. G. (1990). Stable isotope methods for studies of mineral/trace element metabolism. Journal of Nutritional Biochemistry 1, 4-19.

Rios, E., Hunter, R. E., Cook, J. D., Smith, N. J. \& Finch, C. A. (1975). The absorption of iron as supplements in infant cereal and infant formulas. Pediatrics 55, 686-689.

Sevenich, G. J. \& Fritz, J. S. (1985). Effect of complexing agents on the chromatographic separation of polyvalent cations. Journal of Chromatography 347, 147-154. 
Stekel A., Olivares, M., Pizarro, F., Chadud, P., Lopez, I. \& Amar, M. (1986). Absorption of fortification iron from milk formulas in infants. American Journal of Clinical Nutrition 43, 917-922.

Turnlund, J. R. \& Keyes, W. R. (1990). Automated analysis of stable isotopes of zinc, copper, iron, calcium and magnesium by thermal ionization mass spectrometry using double isotope dilution for tracer studies in humans. Journal of Micronutrient Analysis 7, 117-145. 